\title{
Selective measurement of a smooth muscle actin: why $\beta$-actin can not be used as a housekeeping gene when tissue fibrosis occurs
}

\author{
Apor Veres-Székely ${ }^{1 \dagger}$, Domonkos Pap ${ }^{1 \dagger}$, Erna Sziksz ${ }^{1}$, Eszter Jávorszky ${ }^{2,3}$, Réka Rokonay ${ }^{2}$, Rita Lippai ${ }^{2}$, \\ Kálmán Tory ${ }^{2,3}$, Andrea Fekete ${ }^{2,4}$, Tivadar Tulassay ${ }^{1,2}$, Attila J. Szabó1,2 and Ádám Vannay ${ }^{1 *}$
}

\begin{abstract}
Background: Prevalence of fibroproliferative diseases, including chronic kidney disease is rapidly increasing and has become a major public health problem worldwide. Fibroproliferative diseases are characterized by increased expression of a smooth muscle actin (a-SMA) that belongs to the family of the six conserved actin isoforms showing high degree homology. The aim of the present study was to develop real-time PCRs that clearly discriminate a-SMA and ß-actin from other actin isoforms.

Results: Real-time PCRs using self-designed mouse, human and rat specific a-SMA or ß-actin primer pairs resulted in the specific amplification of the artificial DNA templates corresponding to mouse, human or rat a-SMA or $B$-actin, however B-actin showed cross-reaction with the housekeeping $\mathrm{Y}$-cyto-actin. We have shown that the use of improperly designed literary primer pairs significantly affects the results of PCRs measuring mRNA expression of a-SMA or B-actin in the kidney of mice underwent UUO.

Conclusion: We developed a set of carefully designed primer pairs and PCR conditions to selectively determine the expression of mouse, human or rat a-SMA and B-actin isoforms. We demonstrated the importance of primer specificity in experiments where the results are normalized to the expression of $\beta$-actin especially when fibrosis and thus increased expression of a-SMA is occur.
\end{abstract}

Keywords: Fibrosis, Primer design, Real-time PCR, Actin, a-SMA, B-actin

\section{Background}

Incidence of chronic fibroproliferative diseases (FDs) is rapidly increasing and has become a major public health problem worldwide [1]. According to some estimates, about $45 \%$ of all deaths are attributed to FDs in the developed world [2].

The common hallmark of FDs is the activation of myofibroblasts (MFs), which produce excessive amount of extracellular matrix [2-4] leading to the destruction of original tissue architecture and gradual decline of organ function [5]. In response to activation, MFs express a high amount of $\alpha$ smooth muscle actin ( $\alpha$-SMA).

\footnotetext{
*Correspondence: vannay.adam@med.semmelweis-univ.hu

${ }^{\dagger}$ Apor Veres-Székely and Domonkos Pap contributed equally to this work 1 MTA-SE Pediatrics and Nephrology Research Group, Budapest, Hungary Full list of author information is available at the end of the article
}

Accordingly, measuring $\alpha$-SMA expression is widely used to determine the presence and activity of MFs $[6,7]$.

$\alpha$ Smooth muscle actin belongs to the actin gene family consisting six different isoforms also including $\alpha$-cardiacand $\alpha$-skeletal-actin, $\beta$-actin, $\gamma$-cyto- and $\gamma$-smooth-actin. Beside $\alpha$-SMA, $\beta$-actin has a special importance also, as it is a widely used internal control in many molecular biological measurements. Although actin isoforms are encoded by different genes the similarity between them is significant. Indeed, the homology in the amino acid or nucleotide sequences of the different actin isoforms is over $90 \%$ making it a real challenge to selectively measure their expression [8]. Due to the increasing importance of FDs, the mRNA expression of $\alpha$-SMA is frequently determined in thousands of experiments suggesting the importance of the issue. High accuracy, sensitivity and 
easy feasibility of real-time RT-PCR make it the most frequently used method to quantify gene expression in the field of basic and applied research as well [9-11]. Evidences suggest that real-time PCR enable the specific amplification of the target nucleotide sequence even if only one template molecule is present or if the difference is only one base from another nucleotide sequence [12]. In the present study we developed a SYBR Green stain based isoform-specific real-time PCR method to selectively measure the expression of mouse, human or rat $\alpha$-SMA and $\beta$-actin. Moreover, we investigated and unequivocally demonstrated the measurement inaccuracy caused by the use of non-specific $\alpha$-SMA or $\beta$-actin primer pairs in fibrotic kidney samples.

\section{Methods}

\section{Design and alignment of $\mathrm{a}$-SMA and B-actin specific primers}

The mRNA sequences of mouse $\alpha$-SMA (NM_007392.3), human $\alpha$-SMA (NM_001141945.2), rat $\alpha$-SMA (NM_031004.2), mouse B-actin (NM_007393.5), human ß-actin (NM_001101.3), rat ß-actin (NM_031144.3), mouse $\gamma$-cyto-actin (NM_009609.3) and mouse $\gamma$-smooth-actin (NM_009610.2) were collected from NCBI Reference Sequence Database [13]. Our selfdesigned mouse-, human- and rat $\alpha-\mathrm{SMA}\left(\mathrm{m} \alpha-\mathrm{SMA}_{\mathrm{SD}}\right.$, $\left.\mathrm{h} \alpha-\mathrm{SMA}_{\mathrm{SD}}, \mathrm{r} \alpha-\mathrm{SMA}_{\mathrm{SD}}\right)$ or $\beta$-actin $\left(\mathrm{m} \beta\right.$-actin $\mathrm{SD}_{\mathrm{S}}, \mathrm{h} \beta$-act$\mathrm{in}_{\mathrm{SD}}, \mathrm{r} \beta$-actin $\mathrm{SD}_{\mathrm{SD}}$ ) specific primer pairs were designed by Primer3web software version 4.0.0 [14] considering the significant overlap between the mRNA sequences of different actin isoforms (Fig. 1; Table 1). Literary mouse $\alpha$-SMA $\left(m \alpha-\mathrm{SMA}_{\mathrm{L} 1}[15,16], \mathrm{m} \alpha-\mathrm{SMA}_{\mathrm{L} 2}[17,18]\right.$, $\left.m \alpha-\mathrm{SMA}_{\mathrm{L} 3}[19]\right)$ and $\beta$-actin $\left(\mathrm{m} \beta-\operatorname{actin}_{\mathrm{L} 1}[20,21]\right.$, $\mathrm{m} \beta$ $\operatorname{actin}_{\mathrm{L} 2}$ [18], $\mathrm{m} \beta-\operatorname{actin}_{\mathrm{L} 3}$ [22]) specific primer pairs were selected from papers published in different prestigious journals.

\section{Artificial DNA templates}

Artificial templates of mouse $\alpha$-SMA $\left(m \alpha-\mathrm{SMA}_{\mathrm{T}}\right)$,

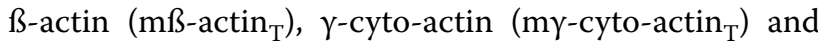
$\gamma$-smooth-actin $\left(\mathrm{m} \gamma\right.$-smooth-actin $\left.{ }_{\mathrm{T}}\right)$ covering all of the annealing sections of the examined primers were synthetized as gBlocks Gene Fragments by Integrated DNA Technologies (Coralville, IA, USA). Human and rat

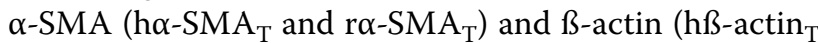
and $\mathrm{r} \beta-\mathrm{actin}_{\mathrm{T}}$ ) DNA templates were synthetized by PCR method using specific human or rat $\alpha$-SMA and $\beta$-actin primers. RT-PCR products were then separated by electrophoresis in $2 \%$ agarose gel. Thereafter, fractions with the required product length were extracted from the gel, purified by SureClean Plus purification kit (Bioline, Taunton, MA, USA) and resolved in RNase-free water.

\section{Unilateral ureteral obstruction (UUO) surgical protocol} The institutional committee on animal welfare approved all experiments (PEI/OO1/83-4/2013). Experiments were performed on 7-8 week old male C57BL/6J mice (Charles River Laboratories, Sulzfeld, Germany). Animals were housed in a temperature-controlled $\left(22 \pm 1{ }^{\circ} \mathrm{C}\right)$ room with alternating light and dark cycles and had free access to standard rodent chow and water. Mice were randomly divided into two groups (Control and UUO;

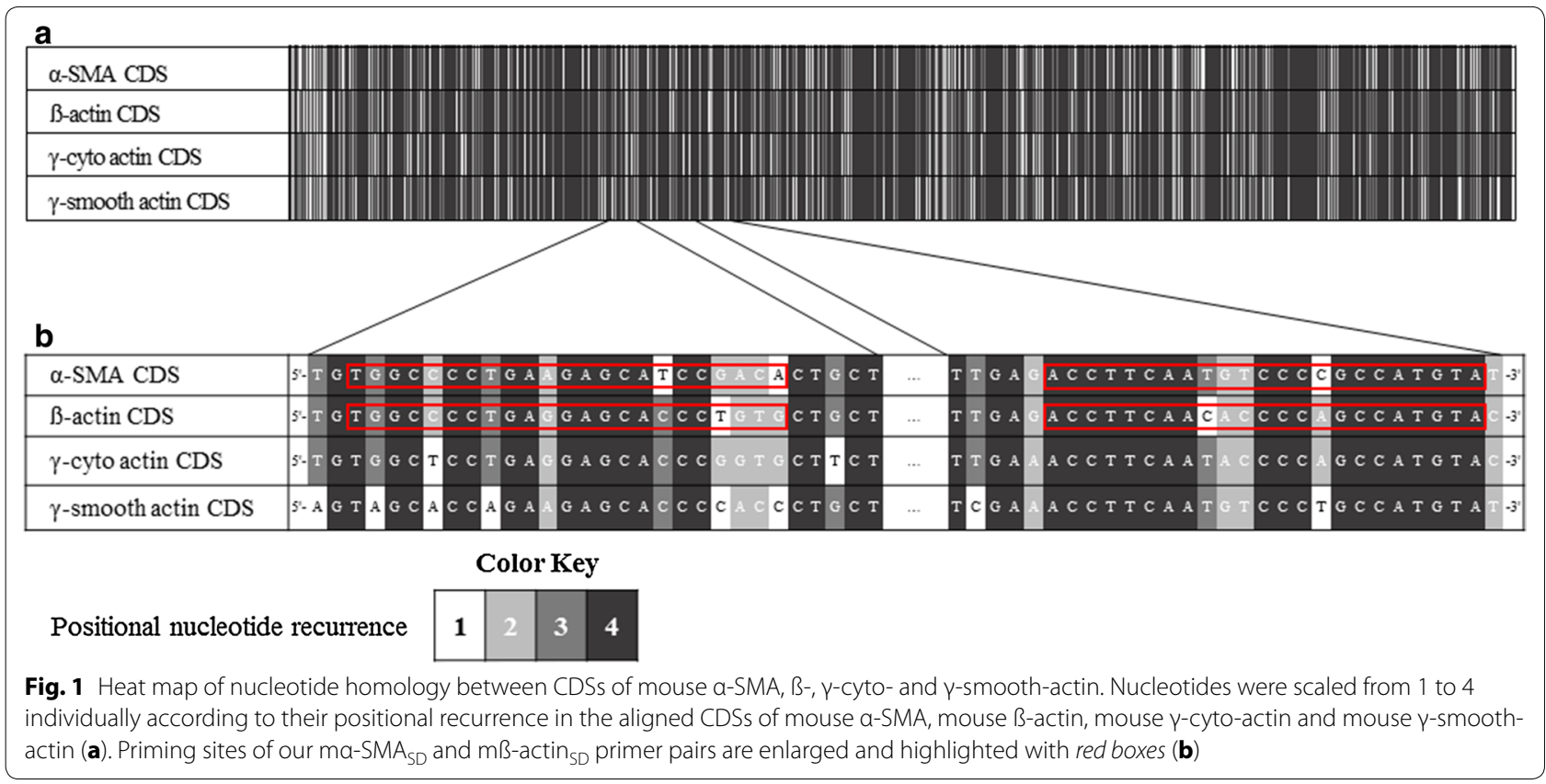


Table 1 Primer sequences and parameters

\begin{tabular}{|c|c|c|c|c|c|}
\hline \multirow{2}{*}{$\begin{array}{l}\text { Name } \\
m a-S M A_{S D}\end{array}$} & \multirow{2}{*}{$\begin{array}{l}\text { Species } \\
\text { Mouse }\end{array}$} & \multicolumn{2}{|c|}{ Primer pairs } & \multirow{2}{*}{$\begin{array}{l}\text { Product length (bp) } \\
105\end{array}$} & \multirow{2}{*}{$\frac{T_{a}\left({ }^{\circ} \mathrm{C}\right)}{60}$} \\
\hline & & F: & 5'-CCCCTGAAGAGCATCGGACA-3' & & \\
\hline & & $\mathrm{R}:$ & 5'-TGGCGGGGACATTGAAGGT-3' & & \\
\hline \multirow[t]{2}{*}{$m ß-\operatorname{actin}_{\mathrm{SD}}$} & Mouse & $\mathrm{F}:$ & 5'-CCCCTGAGGAGCACCGTGTG-3' & 106 & 60 \\
\hline & & $\mathrm{R}:$ & 5'-ATGGCTGGGGTGTTGAAGGT-3' & & \\
\hline \multirow{2}{*}{$m a-S M A_{L 1}$} & Mouse & $\mathrm{F}:$ & $5^{\prime}$-CACTATTGGCAACGAGCGC-3' & 60 & 48 \\
\hline & & R: & 5'-CCAATGAAGGAAGGCTGGAA-3' & & \\
\hline \multirow[t]{2}{*}{$\mathrm{ma}_{-} \mathrm{SMA} \mathrm{L}_{\mathrm{L} 2}$} & Mouse & F: & 5'-GTCCCAGACATCAGGGAGTAA-3' & 101 & 57 \\
\hline & & $\mathrm{R}:$ & 5'-TCGGATACTTCAGCGTCAGGA-3' & & \\
\hline \multirow[t]{2}{*}{$\mathrm{ma}^{-S M A_{L 3}}$} & Mouse & F: & $5^{\prime}-$ GAGGCACCACTGAACCCTAA-3' & 154 & 54 \\
\hline & & $\mathrm{R}:$ & 5'-CATCTCCAGAGTCCAGCACA-3' & & \\
\hline \multirow[t]{2}{*}{$m ß-\operatorname{actin}_{\mathrm{L} 1}$} & Mouse & F: & 5'-GGCTGTATTCCCCTCCATCG-3' & 154 & 56 \\
\hline & & $\mathrm{R}:$ & 5'-CCAGTTGGTAACAATGCCATGT-3' & & \\
\hline \multirow[t]{2}{*}{$m ß-\operatorname{actin}_{\mathrm{L} 2}$} & Mouse & $\mathrm{F}:$ & 5'-TGTTACCAACTGGGACGACA-3' & 165 & 55 \\
\hline & & $\mathrm{R}:$ & 5'-GGGGTGTTGAAGGTCTCAAA-3' & & \\
\hline \multirow[t]{2}{*}{$m ß-\operatorname{actin}_{\llcorner 3}$} & Mouse & F: & 5'-AGCCATGTACGTAGCCATCC-3' & 228 & 57 \\
\hline & & $\mathrm{R}:$ & 5'-CTCTCAGCTGTGGTGGTGAA-3' & & \\
\hline \multirow[t]{2}{*}{ RN18S } & Mouse & F: & 5'-AGCGGTCGGCGTCCCCCAACTTCT-3' & 107 & 60 \\
\hline & & $\mathrm{R}:$ & 5'-GCGCGTGCAGCCCCGGACATCTA-3' & & \\
\hline \multirow[t]{2}{*}{ ha-SMA $A_{S D}$} & Human & F: & 5'-ACTGAGCGTGGCTATTCCTCCGTT-3' & 111 & 58 \\
\hline & & $\mathrm{R}:$ & 5'-GCAGTGGCCATCTCATTTTCA-3' & & \\
\hline \multirow[t]{2}{*}{$\mathrm{h} ß-\operatorname{actin}_{\mathrm{SD}}$} & Human & F: & 5'-ACCGAGCGTGGCTACAGCTTCACC-3' & 114 & 53 \\
\hline & & $\mathrm{R}:$ & 5'-AGCACCCGTGGCCATCTCTTTCTCG-3' & & \\
\hline \multirow[t]{2}{*}{$\mathrm{ra}-S M A_{S D}$} & Rat & $\mathrm{F}:$ & 5'-GAGCGTGGCTATTCCTTCGTG-3' & 106 & 54 \\
\hline & & $\mathrm{R}:$ & 5'-CAGTGGCCATCTCATTTTCAAAGT-3' & & \\
\hline \multirow[t]{2}{*}{$r ß-\operatorname{actin}_{S D}$} & Rat & $\mathrm{F}:$ & $5^{\prime}$-ACCGAGCATGGCTACAGCGTCACC-3' & 106 & 54 \\
\hline & & $\mathrm{R}:$ & 5'-GTGGCCATCTCTTGCTCGGAGTCT-3' & & \\
\hline
\end{tabular}

Nucleotide sequences of forward (F) and reverse (R) primers, product lengths and specific optimal annealing temperatures ( $\mathrm{T}_{\mathrm{a}}$ ) applied for the real-time PCR detection

$n=6$ /groups). After general anesthesia mice were placed on a thermo-controlled table to maintain rectal temperature at $37 \pm 1{ }^{\circ} \mathrm{C}$. After standard midline laparotomy, the bowel was gently displaced from the abdomen and covered with saline soaked sterile gauze. Then the left ureter of animals in the UUO group was isolated by blunt dissection and completely ligated using fine suture material. The bowel was then laid back and the muscle and skin were closed with 4-0 nylon sutures. Sham-operated control animals underwent identical surgical procedure without occlusion of the left ureter. Seven days after the initiation of UUO left kidneys were surgically removed, immediately snap-frozen and stored at $-80{ }^{\circ} \mathrm{C}$ for further analysis.

\section{RNA isolation and CDNA synthesis}

Total RNA was isolated from kidney samples of mice underwent UUO and sham-operated controls by Total RNA Mini Kit (Geneaid Biotech Ltd., New Taipei City, Taiwan) according to the instructions of the manufacturer. The concentration and quality of the isolated RNA was determined by DeNovix DS-11 spectrophotometer (DeNovix Inc., Wilmington, DE, USA). $500 \mathrm{ng}$ of total RNA was reverse-transcribed using Maxima First Strand cDNA Synthesis Kit for RT-qPCR (Thermo Fisher Scientific, Waltham, MA, USA) to generate first-stranded cDNA.

\section{Real-time polymerase chain reaction}

The expression of $\alpha$-SMA and $\beta$-actin was measured by real-time PCR on a Light Cycler 480 system (Roche Diagnostics, Mannheim, Germany). The reaction mix contained $10 \mathrm{pmol} / \mu \mathrm{l}$ of self-designed or literary forward and reverse PCR primers (Table 1; Integrated DNA Technologies, Coralville, Iowa, USA), $10 \mu \mathrm{l}$ of Light Cycler 480 SYBR Green I Master enzyme mix (Roche Diagnostics, Mannheim, Germany) and $1 \mu \mathrm{l}$ of the corresponding artificial DNA templates $(0.1 \mathrm{nM})$ or cDNA. Nucleotide sequences of the applied primer pairs, their specific optimal annealing temperatures and product length are 
shown in Table 1 . Results were analyzed by Light-Cycler 480 software version 1.5.0.39 (Roche Diagnostics, Mannheim, Germany). PCR products were separated by electrophoresis in 2\% agarose gel (Bioline, London, UK) using 1X Tris-borate-EDTA buffer. Gels were stained with GelRed (Biotium, Hayward, Ca, USA) and were visualized and documented by VersaDoc 5000MP (BioRad Laboratories, Hercules, CA, USA). Product lengths were determined using GeneRuler 100 bp DNA Ladder (Thermo Fisher Scientific, Waltham, MA, USA).

In each PCR the mRNA expression of $\alpha$-SMA and $ß$-actin was determined by comparison with the expression of $18 \mathrm{~S}$ ribosomal RNA (RN18S) as internal control from the same samples using the $\Delta \Delta \mathrm{Ct}$ method. The data were normalized and presented as the ratio of their control values.

To determine the efficiency of real-time PCRs using

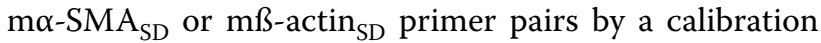
curve, we applied a tenfold dilution series (from $10 \mathrm{nM}$

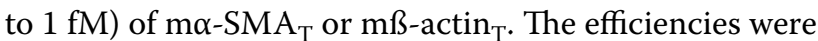
calculated by Light-Cycler 480 software version 1.5.0.39 (Roche Diagnostics, Mannheim, Germany).

\section{Sequencing of PCR products}

The products of our $\alpha$-SMA and $\beta$-actin specific realtime PCRs amplifying cDNA samples derived from the kidneys of mice underwent UUO were purified by SureClean Plus purification kit (Bioline, Taunton, MA, USA) and sequenced using BrightDye Terminator Cycle Sequencing Kit (Nimagen, Nijmegen, The Netherlands) according to the instructions of the manufacturer. Sanger sequencing was performed on ABI 3500 sequencer (Thermo Fischer Scientific, Waltham, MA, USA) and chromatograms were analyzed by Unipro UGENE software version 1.16.1. (UniPro, Novosibrisk, Russia).

\section{Statistical analysis}

The statistical evaluation and presentation of the normalized, relative mRNA expressions were performed by GraphPad Prism 6.01 software (GraphPad Software Inc., La Jolla, CA, USA). After testing normality with Kolmogorov-Smirnov test, unpaired $t$ test or Mann-Whitney U test was used to determine the differences between the groups (Table 2). $\mathrm{p} \leq 0.05$ was considered as statistically significant. Values were expressed as mean + standard deviation (SD).

To determine the correlation between the relative mRNA expressions, Pearson correlation analysis was performed. Interpretation of Pearson correlation coefficient (r) [23] is summarized in Table 3. $\mathrm{p} \leq 0.05$ was considered as statistically significant.

\section{Results}

Template specificity of ma-SMA SD $_{\text {and }} \mathrm{m} ß$-actin $_{\text {SD }}$ primer pairs To investigate the specificity of $\mathrm{m} \alpha-\mathrm{SMA}_{\mathrm{SD}}$ and $\mathrm{m} \beta$-actin $_{\mathrm{SD}}$ primer pairs real-time PCR was performed where artificial DNA oligos corresponding to mouse $\alpha$-SMA,

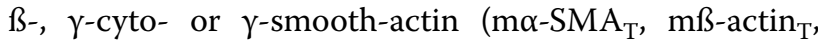
$\gamma$-cyto-actin ${ }_{\mathrm{T}}$ and $\mathrm{m} \gamma$-smooth-actin ${ }_{\mathrm{T}}$ ) served as templates. According to our expectations, PCRs using our m $\alpha-\mathrm{SMA}_{\mathrm{SD}}$ primer pair amplified the $\mathrm{m} \alpha-\mathrm{SMA}_{\mathrm{T}}$ DNA template and resulted in a product with single melting peak at $83.4{ }^{\circ} \mathrm{C}$ and a discrete band at $105 \mathrm{bp}$ in agarose gel electrophoresis (Fig. 2a, e and f), but did not amplified

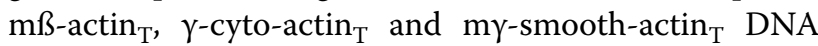
templates (Fig. 2b-f). Similarly, PCRs using mß-actin ${ }_{\mathrm{SD}}$ primer pair amplified the $\mathrm{mß}$-actin $\mathrm{T}_{\mathrm{T}}$ and $\gamma$-cyto-actin ${ }_{\mathrm{T}}$ DNA templates and resulted in the same products with melting peaks at 84.8 and $83.3{ }^{\circ} \mathrm{C}$ and bands at $106 \mathrm{bp}$ (Fig. 3b, c, e and f), but did not amplify ma-SMA ${ }_{\mathrm{T}}$ and my-smooth-actin ${ }_{\mathrm{T}}$ DNA templates (Fig. 3a, d-f).

Table 2 Statistical analysis of mRNA expression of a-SMA and ß-actin in mice kidneys underwent UUO

\begin{tabular}{|c|c|c|c|c|c|}
\hline \multirow[t]{3}{*}{ Applied primer } & \multicolumn{2}{|l|}{ Normality test } & \multicolumn{3}{|c|}{ Comparison test (control vs. UUO) } \\
\hline & \multirow[t]{2}{*}{ Test } & \multicolumn{2}{|l|}{ P value } & \multirow[t]{2}{*}{ Test } & \multirow[t]{2}{*}{ P value } \\
\hline & & Control & UUO & & \\
\hline $\mathrm{ma} \mathrm{SMA} \mathrm{A}_{\mathrm{SD}}$ & Kolmogorov-Smirnov & 0.2 & 0.2 & Unpaired t test & $<0.0001$ \\
\hline $\mathrm{ma}-\mathrm{SMA} \mathrm{L}_{\mathrm{L} 1}$ & Kolmogorov-Smirnov & 0.0115 & 0.2 & Mann-whitney U test & 0.0023 \\
\hline$m a-S M A_{L 2}$ & Kolmogorov-Smirnov & 0.2 & 0.2 & Unpaired t test & $<0.0001$ \\
\hline$m a-S M A_{L 3}$ & Kolmogorov-Smirnov & 0.2 & 0.2 & Unpaired t test & $<0.0001$ \\
\hline $\mathrm{m} ß-\operatorname{actin}_{\mathrm{SD}}$ & Kolmogorov-Smirnov & 0.1283 & 0.2 & Unpaired t test & 0.4187 \\
\hline mß-actin ${ }_{\mathrm{L} 1}$ & Kolmogorov-Smirnov & 0.2 & 0.2 & Unpaired t test & 0.0022 \\
\hline $\mathrm{m} ß-$ actin $_{\mathrm{L} 2}$ & Kolmogorov-Smirnov & 0.2 & 0.2 & Unpaired t test & 0.0047 \\
\hline $\mathrm{m} ß-\operatorname{actin}_{\mathrm{L} 3}$ & Kolmogorov-Smirnov & 0.2 & 0.2 & Unpaired t test & 0.0021 \\
\hline
\end{tabular}

The mRNA expression of a-SMA and ß-actin was determined by comparison with the expression of 18S ribosomal RNA (RN18S) as internal control from the same samples using the $\Delta \Delta \mathrm{Ct}$ method 
Table 3 Interpretation of Pearson correlation coefficients

\begin{tabular}{ll}
\hline Size of correlation coefficient & Interpretation \\
\hline $0.9 \leq r \leq 1$ & Very high positive correlation \\
$0.7 \leq r \leq 0.9$ & High positive correlation \\
$0.5 \leq r \leq 0.7$ & Moderate positive correlation \\
$0.3 \leq r \leq 0.5$ & Low positive correlation \\
$0 \leq r \leq 0.3$ & Negligible correlation \\
\hline
\end{tabular}

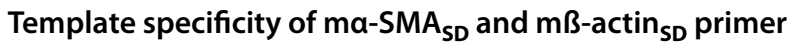
pairs

To investigate the specificity of our $\mathrm{m} \alpha-\mathrm{SMA}_{\mathrm{SD}}$ and $\mathrm{m} \beta$ actin $_{\mathrm{SD}}$ primer pairs, real-time PCRs were performed using cDNA templates generated from mice kidneys underwent ureteral obstruction. The subsequent Sanger sequencing of the PCR products demonstrated that the nucleotide sequences were identical with the reference nucleotide sequences ( $\alpha$-SMA: NM_007392.3; ß-actin: NM_007393.5) (Fig. 4).

\section{Amplification efficiency of real-time PCRs}

Efficiencies derived from the slopes of calibration curves using $\mathrm{m} \alpha-\mathrm{SMA}_{\mathrm{SD}}$ or $\mathrm{m} ß$-actin $\mathrm{SD}$ were 2.123 or 2.077, respectively (Fig. 5).

\section{Specificity of literary primer pairs used to determine the expression of mouse $\boldsymbol{\alpha}$-SMA or $ß$-actin}

The nucleotide sequence of all literary primers show significant overlap with the coding sequence (CDS) both of
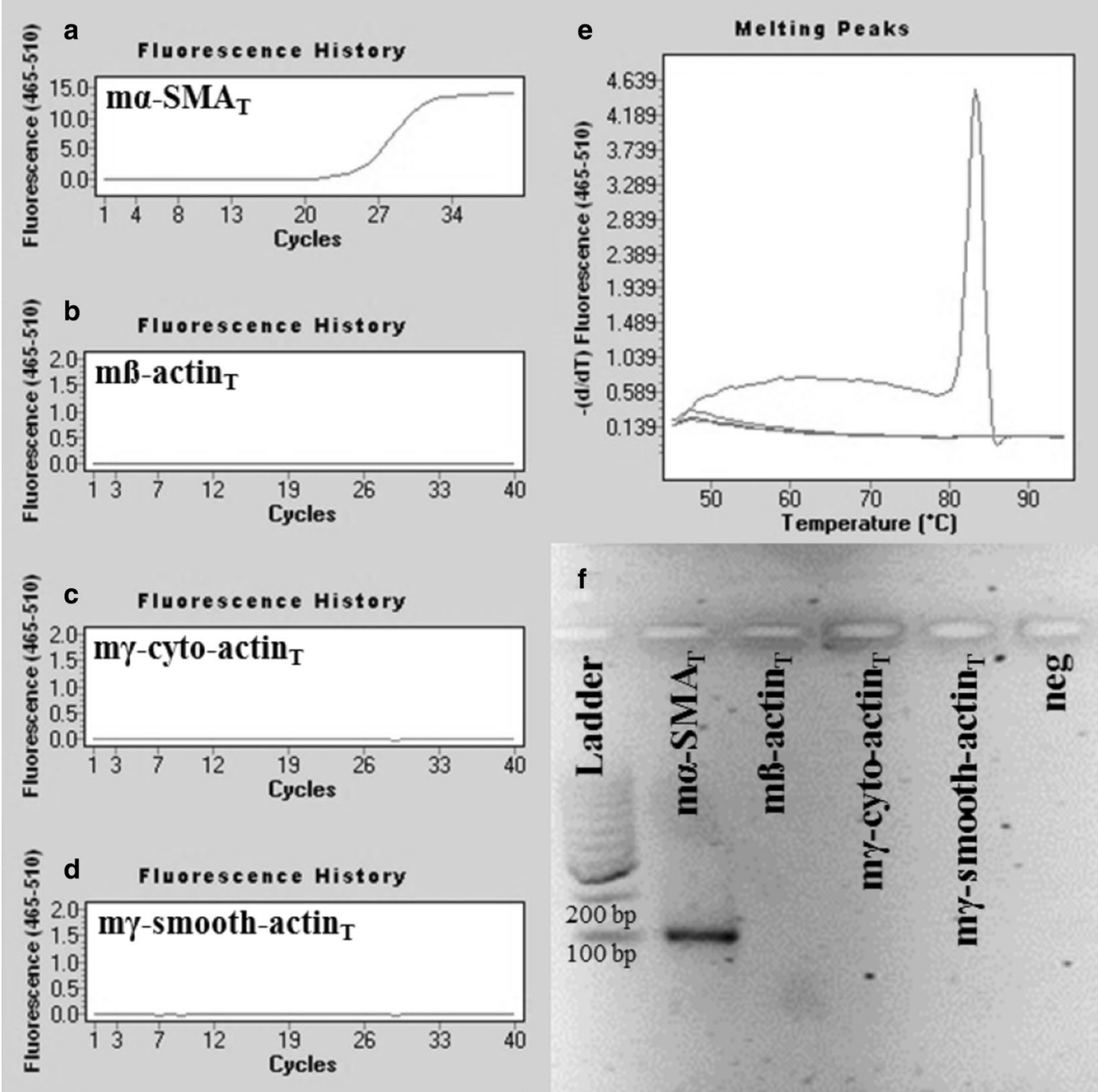

Fig. 2 Representative plots of mouse a-SMA specific real-time PCRs. PCRs using ma-SMA $A_{S D}$ primer pair amplified ma-SMA $A_{T}$ artificial DNA template

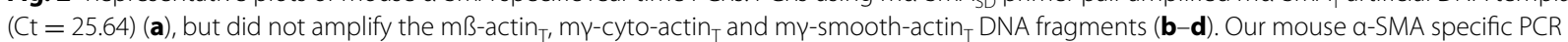
resulted in a product with single melting peak at $83.4^{\circ} \mathrm{C}(\mathbf{e})$ and in one discrete band at $105 \mathrm{bp}$ in agarose gel after electrophoresis (f) 


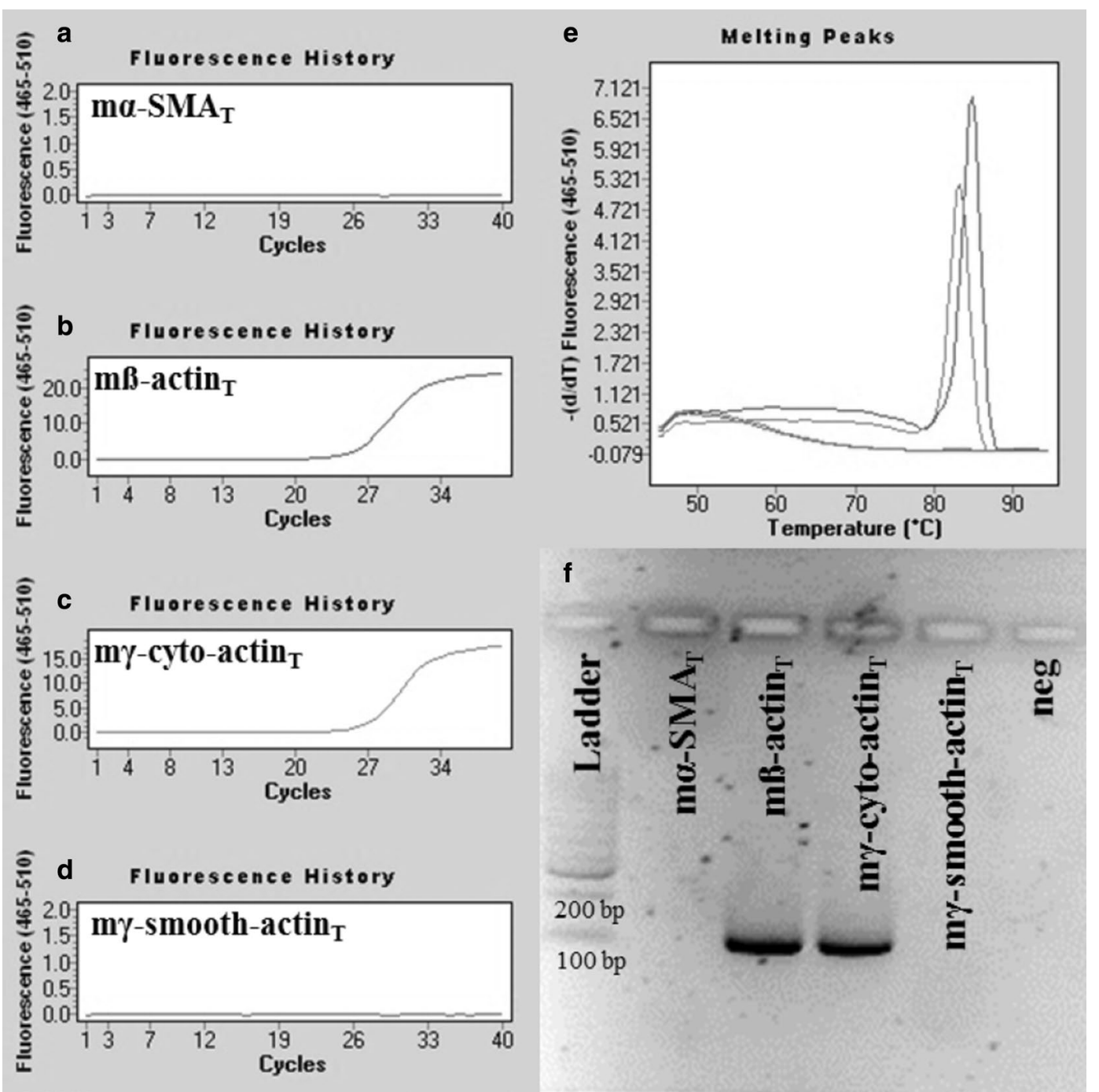

Fig. 3 Representative plots of mouse $\beta$-actin specific real-time PCRs. PCRs using $m ß$-actin SD $_{\text {primer pair amplified } m ß \text {-actin }}(C t=15.76)$ and

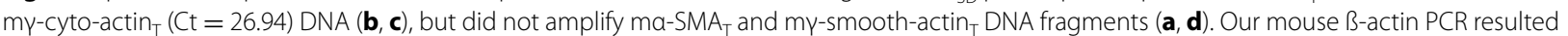
in products with melting peaks at 84.8 and $83.3^{\circ} \mathrm{C}(\mathbf{e})$ and a discrete band at $106 \mathrm{bp}$ in agarose gel after electrophoresis (f)

$\alpha$-SMA and of $\beta$-actin (Fig. 6). To test the specificity of the literary primers (Table 1), real-time PCRs were performed using artificial DNA templates corresponding to mouse $\alpha$-SMA and $\beta$-actin $\left(m \alpha-\mathrm{SMA}_{\mathrm{T}}, \mathrm{m} \beta\right.$-actin $\left.{ }_{\mathrm{T}}\right)$ as well. According to our expectations, all randomly selected literary mouse $\alpha$-SMA $\left(m \alpha-\mathrm{SMA}_{\mathrm{L} 1}, \mathrm{~m} \alpha-\mathrm{SMA}_{\mathrm{L} 2}\right.$ and $\left.m \alpha-S_{M A} A_{L}\right)$ and $\beta$-actin $\left(m \beta-\operatorname{actin}_{L 1}, m \beta\right.$-actin ${ }_{L 2}$ and $\mathrm{m} ß$-actin $\mathrm{L}_{\mathrm{L}}$ ) primer pairs amplified the corresponding specific DNA templates, but also showed a varying degree of cross-reactivity with the non-specific templates (Figs. 7, 8).

Real-time PCRs using $m \alpha-\mathrm{SMA}_{\mathrm{L} 1}, \mathrm{~m} \alpha-\mathrm{SMA}_{\mathrm{L} 2}$, or $m \alpha-\mathrm{SMA}_{\mathrm{L} 3}$ primer pairs and $\mathrm{m} \alpha-\mathrm{SMA}_{\mathrm{T}}$ DNA template resulted in products with single melting peaks at $82,81.9$, or $83.3^{\circ} \mathrm{C}$ and one discrete band at 60,101 , or $154 \mathrm{bp}$ in agarose gel electrophoresis (Fig. 7a-c). However, realtime PCRs using the same literary mouse $\alpha$-SMA primer pairs unspecifically amplified $m ß-$ actin $_{T}$ DNA templates also, resulted in the above listed melting peaks and electrophoretic bands, respectively (Fig. 7a-c).

Real-time PCRs using $\mathrm{m} ß$ actin $_{\mathrm{L1}}, \mathrm{m} \beta$-actin $\mathrm{L}_{\mathrm{L} 2}$, or

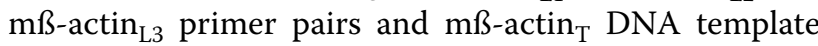
resulted in products with single melting peaks at 85.6, 86.3 , or $87.4{ }^{\circ} \mathrm{C}$ and one discrete band at 60,101 , or $154 \mathrm{bp}$ in agarose gel electrophoresis (Fig. 8a-c). However, real-time PCRs using the same literary mouse $ß$-actin primers unspecifically amplified $m \alpha-\mathrm{SMA}_{\mathrm{T}} \mathrm{DNA}$ templates also, resulted in the above listed melting peaks and electrophoretic bands, respectively (Fig. 8a-c). 


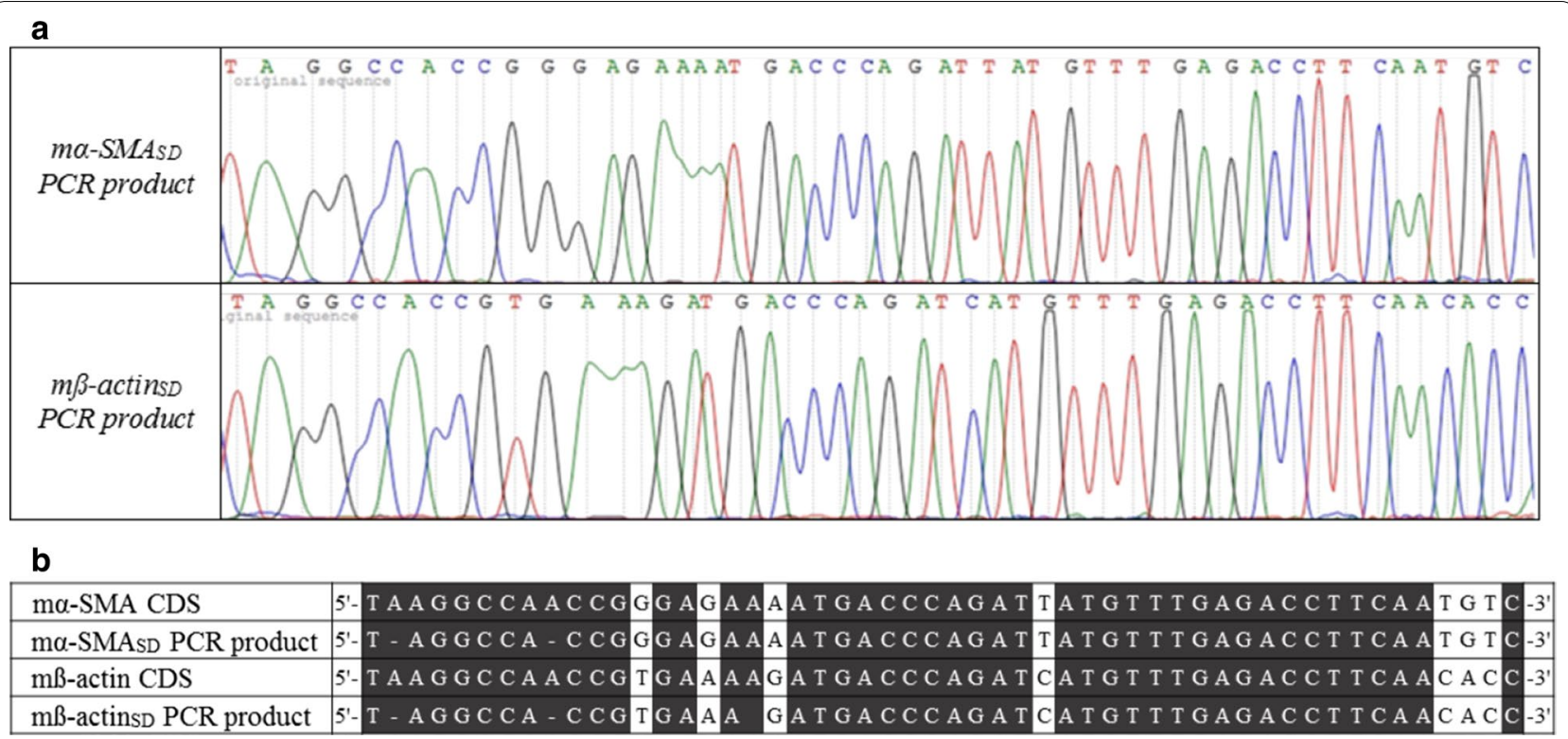

Fig. 4 Sanger sequencing chromatograms of PCR products amplified by $m a-S M A_{S D}$ and $m B$-actin ${ }_{S D}$ primer pairs. $C D N A$ samples derived from kidneys of mice underwent unilateral ureteral obstruction were amplified using ma-SMA $\mathrm{A}_{S \mathrm{D}} \mathrm{Or} B$-actin $\mathrm{SD}_{\mathrm{SD}}$ primer pair and products were sequenced (a). Nucleotide homology between the sequence of our PCR products and the known CDSs of mouse a-SMA or B-actin was complete (b)

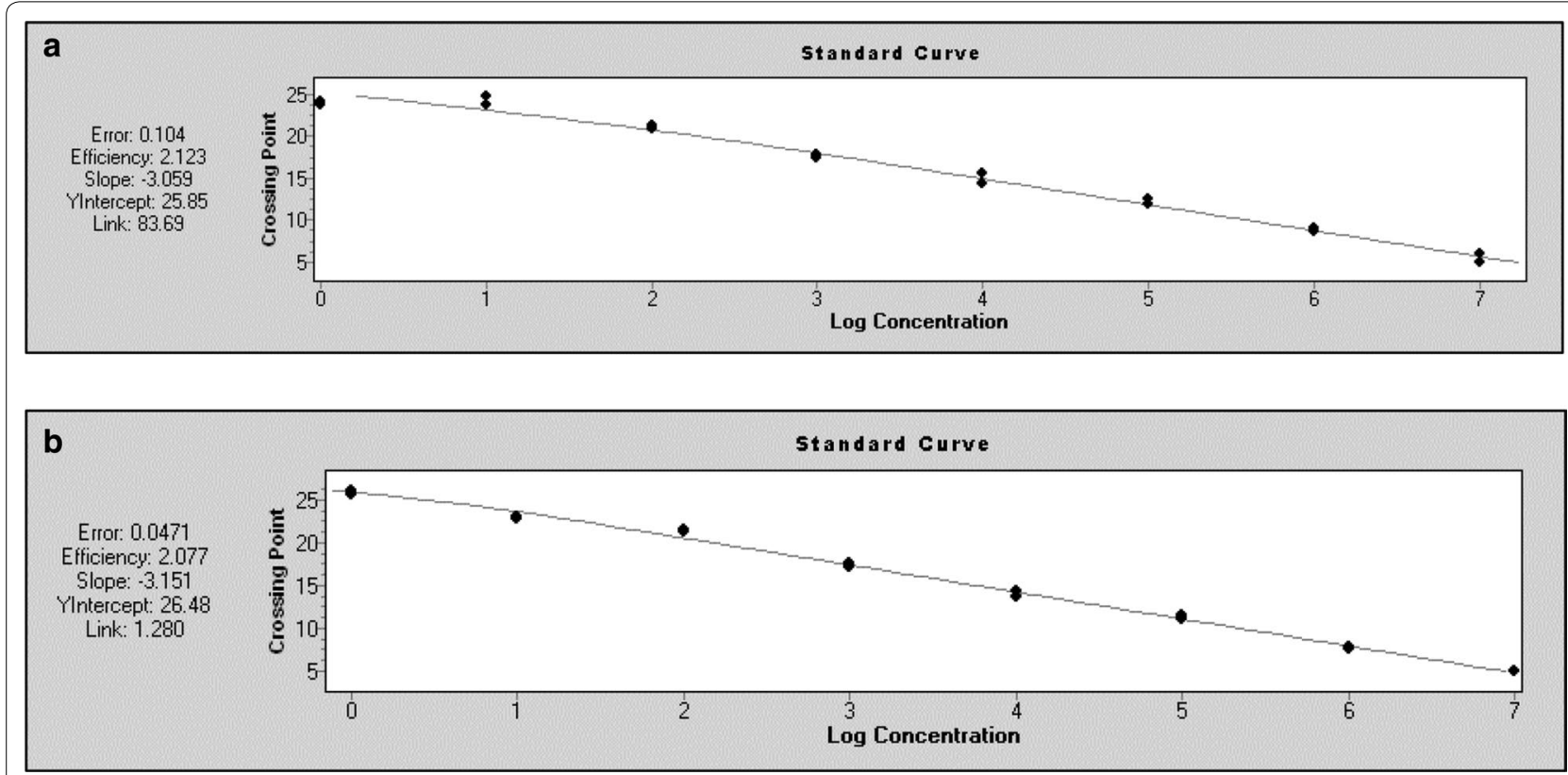

Fig. 5 Amplification efficiency of real-time PCRs. Using ma-SMA $A_{S D}(\mathbf{a})$ or $m ß-a c t i n{ }_{S D}(\mathbf{b})$ primer pairs, tenfold dilution series of ma-SMA or $_{T} \beta_{-}$ actin $_{T}$ solutions served as template

mRNA expression of $a-S M A$ and $B$-actin in mice kidneys underwent UUO

To investigate the effect of the primer specificity on the experimental results, real-time RT-PCRs were performed on kidney samples of mice underwent UUO and sham-operated controls. Using our self-designed or one of the three literary $\alpha$-SMA specific primer pairs, the increase of the $\alpha$-SMA mRNA expression in the UUO group varied from 3.1- to 6.2-fold compared to the corresponding controls (Fig. 9a). 


\begin{tabular}{|c|c|}
\hline \multicolumn{2}{|l|}{$\mathrm{m} \alpha-\mathrm{SMA}_{\mathrm{L} 1}$} \\
\hline$\alpha-S M A$ CDS & 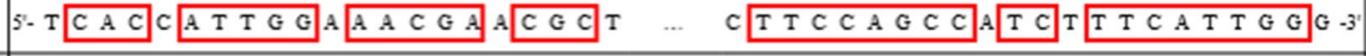 \\
\hline ß-actin CDS & 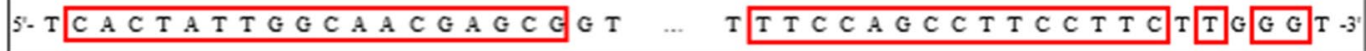 \\
\hline \multicolumn{2}{|l|}{$\mathrm{m} \alpha-\mathrm{SMA}_{\mathrm{L} 2}$} \\
\hline$\alpha-S M A$ CDS & 5. C GTCCCAGACATCAGGGAGTAAT … A TCCTGACGCTGAAGTATCCGAT $3^{\circ}$ \\
\hline ß-actin CDS & 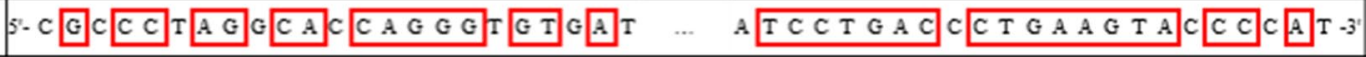 \\
\hline \multicolumn{2}{|l|}{$\mathrm{m} \alpha-\mathrm{SMA}_{\mathrm{L} 3}$} \\
\hline$\alpha-S M A$ CDS & 5. A GAGCACCACTGAACCCTAAG … TTGTGCTGGACTCTGGAGATGG-3 \\
\hline ß-actin CDS & 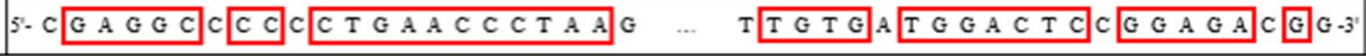 \\
\hline \multicolumn{2}{|l|}{$\mathrm{m} \beta$-actin $\mathrm{L} 1$} \\
\hline$\alpha-S M A$ CDS & 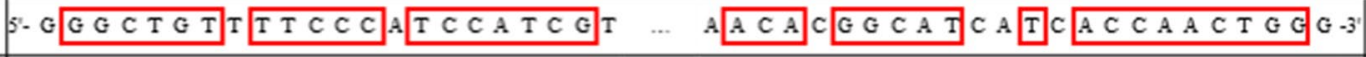 \\
\hline ß-actin CDS & 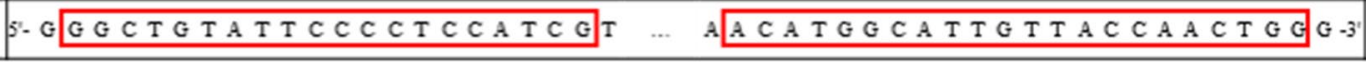 \\
\hline \multicolumn{2}{|l|}{$\mathrm{m} \beta-\operatorname{actin}_{\mathrm{L} 2}$} \\
\hline$\alpha-S M A$ CDS & 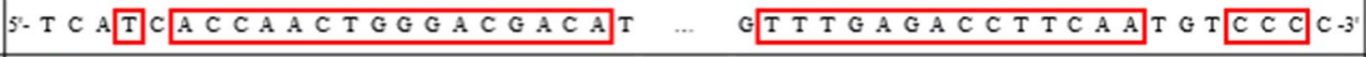 \\
\hline ß-actin CDS & 5. T T T TACAACTGGGACGACAT … GT TGAGACCTTCAACACCCCA-3 \\
\hline \multicolumn{2}{|l|}{$\mathrm{m} \beta-\operatorname{actin}_{\mathrm{L} 3}$} \\
\hline$\alpha-S M A$ CDS & 5. C C G C C A T G T AT G T G C T A T T C A \\
\hline ß-actin CDS & 5. CAGCCATGTACGTAGCCATCCA … CTTCACCACCACAGCTGAGAGG-3 \\
\hline
\end{tabular}

Fig. 6 Priming sites of literary primer pairs aligned to the CDS of mouse a-SMA and ß-actin. Nucleotide sequence of CDSs corresponding to the examined literary primers are highlighted with red boxes

Similarly, marked differences were observed between the renal $B$-actin mRNA expression values of the same kidney samples using the different literary or our selfdesigned $ß$-actin primers. Real-time RT-PCR using our $\mathrm{mß}$-actin $_{\mathrm{SD}}$ primer pair showed no significant changes in the renal $B$-Actin mRNA expression between the UUO and control groups ( $\mathrm{p}=\mathrm{NS}$ vs. control). On the contrary, significantly higher mRNA expression of $ß$-actin was observed in the UUO group in each real-time RT-PCR experiments using literary primer pairs $(\mathrm{p}<0.05$ vs. control) (Fig. 9b).

Investigating the correlation between increased expression of $\alpha$-SMA and $\beta$-actin we found that there is only negligible, non-significant correlation between relative expression of $\alpha$-SMA and $\beta$-actin using our $\mathrm{m} \beta$-actin primers $(r=0.185, p=0.5552$, Fig. 10a). However, we found high positive, significant correlation in case of $\mathrm{m} ß$ $\operatorname{actin}_{\mathrm{L} 1}(\mathrm{r}=0.7086, \mathrm{p}=0.0067$, Fig. 10b), $m ß-$ Actin $_{12}(r=0.7844, p=0.0015$, Fig. 10c $)$ and $m ß-$ $\operatorname{actin}_{\mathrm{L} 3}(\mathrm{r}=0.8242, \mathrm{p}=0.0005$, Fig. 10c $)$ as well.

\section{Template specificity of ha-SMA $A_{S D}$, ra-SMA $A_{S D}, \mathrm{~h} B-\operatorname{actin}_{S D}$ and $\mathrm{r} ß$-actin ${ }_{S D}$ primer pairs}

To investigate the specificity of our h $\alpha-\mathrm{SMA}_{\mathrm{SD}}, \mathrm{r} \alpha-\mathrm{SMA}_{\mathrm{SD}}$,

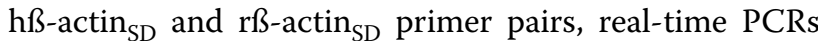

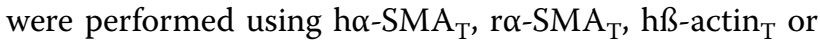
$\mathrm{r} \beta$-actin ${ }_{\mathrm{T}} \mathrm{DNA}$ templates. According to our expectations, our $h \alpha-\mathrm{SMA}_{\mathrm{T}}$ and $\mathrm{r} \alpha-\mathrm{SMA}_{\mathrm{T}}$ primer pairs amplified only the corresponding DNA template resulted in products with single melting peaks at $81.7^{\circ} \mathrm{C}$ (Fig. 11a) or $82.8^{\circ} \mathrm{C}$ (Fig. 11b), but did not amplified $\beta$-actin DNA templates (Fig. 11a, b). Similarly, PCRs using our hß-actin ${ }_{\mathrm{SD}}$ or rßactin $_{\mathrm{SD}}$ primer pairs also amplified the corresponding DNA template only, resulted in products with single melting peaks at $86{ }^{\circ} \mathrm{C}$ (Fig. 11c) or $83.4{ }^{\circ} \mathrm{C}$ (Fig. 11d) but did not amplified the $\alpha$-SMA DNA templates (Fig. 11c and d). 

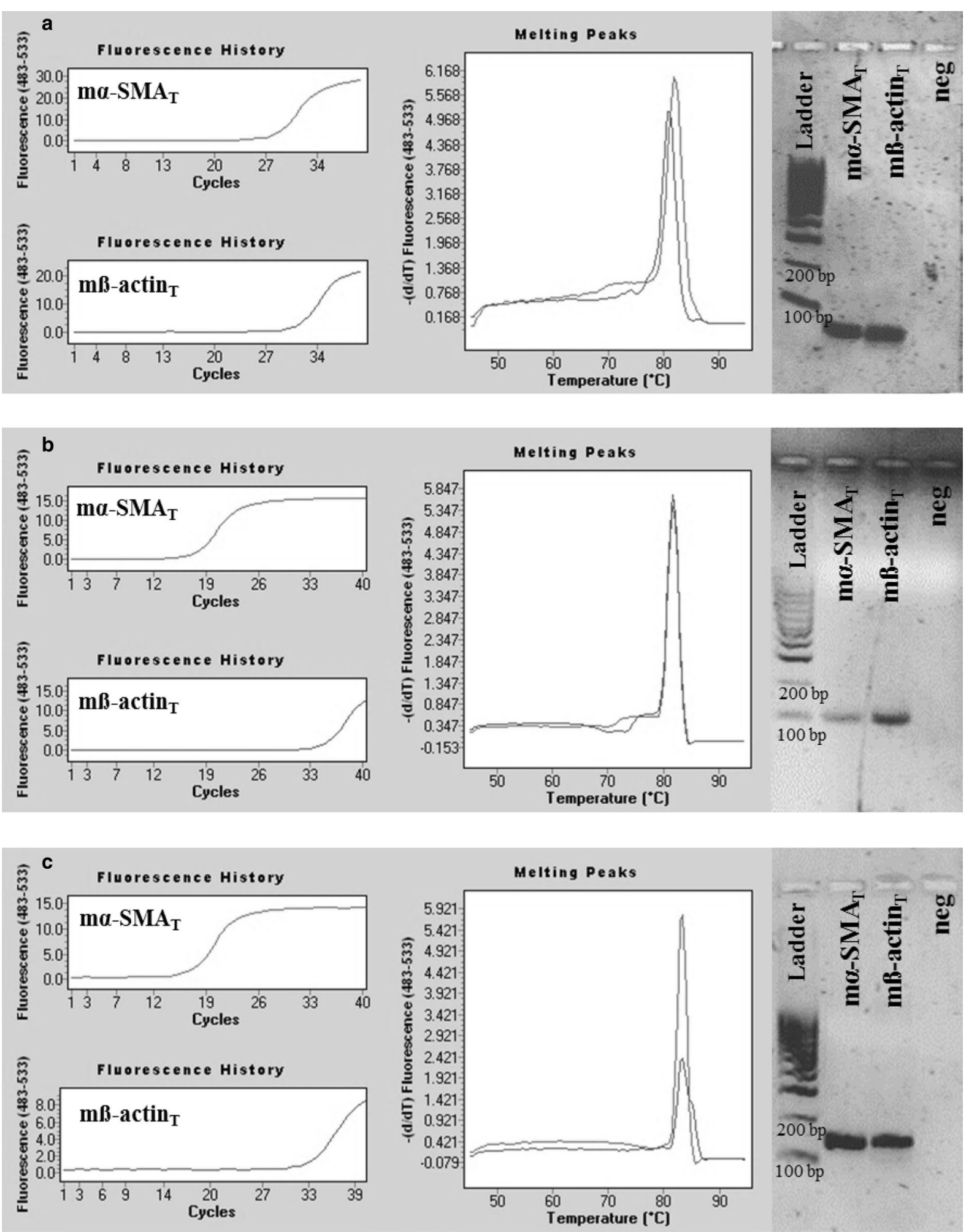

Fig. 7 Representative plots of real-time PCRs using literary primer pairs specific for mouse a-SMA. Real-time PCRs using ma-SMA $\mathrm{A}_{L 1}, \mathrm{ma}^{-S M A_{L 2}}$ or ma-SMA $A_{L 3}$ primer pairs and ma-SMA $D$ DNA templates resulted in products $\left(C t_{L 1}=28.09, C t_{L 2}=17.19, C t_{L 3}=16.79\right)$ with single melting peaks at

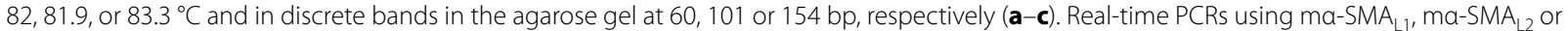
ma-SMA $_{L 3}$ literary primer pairs amplified the non-specific mß-actin ${ }_{T} D N A$ templates also $\left(C_{L} t_{L 1}=31.09, C t_{L 2}=34.62, C t_{L 3}=32.96\right)$, resulted in melting peaks at $81,81.9$, or $83.3^{\circ} \mathrm{C}$ and in discrete bands at 60,101 or $154 \mathrm{bp}$, respectively (a-c) 

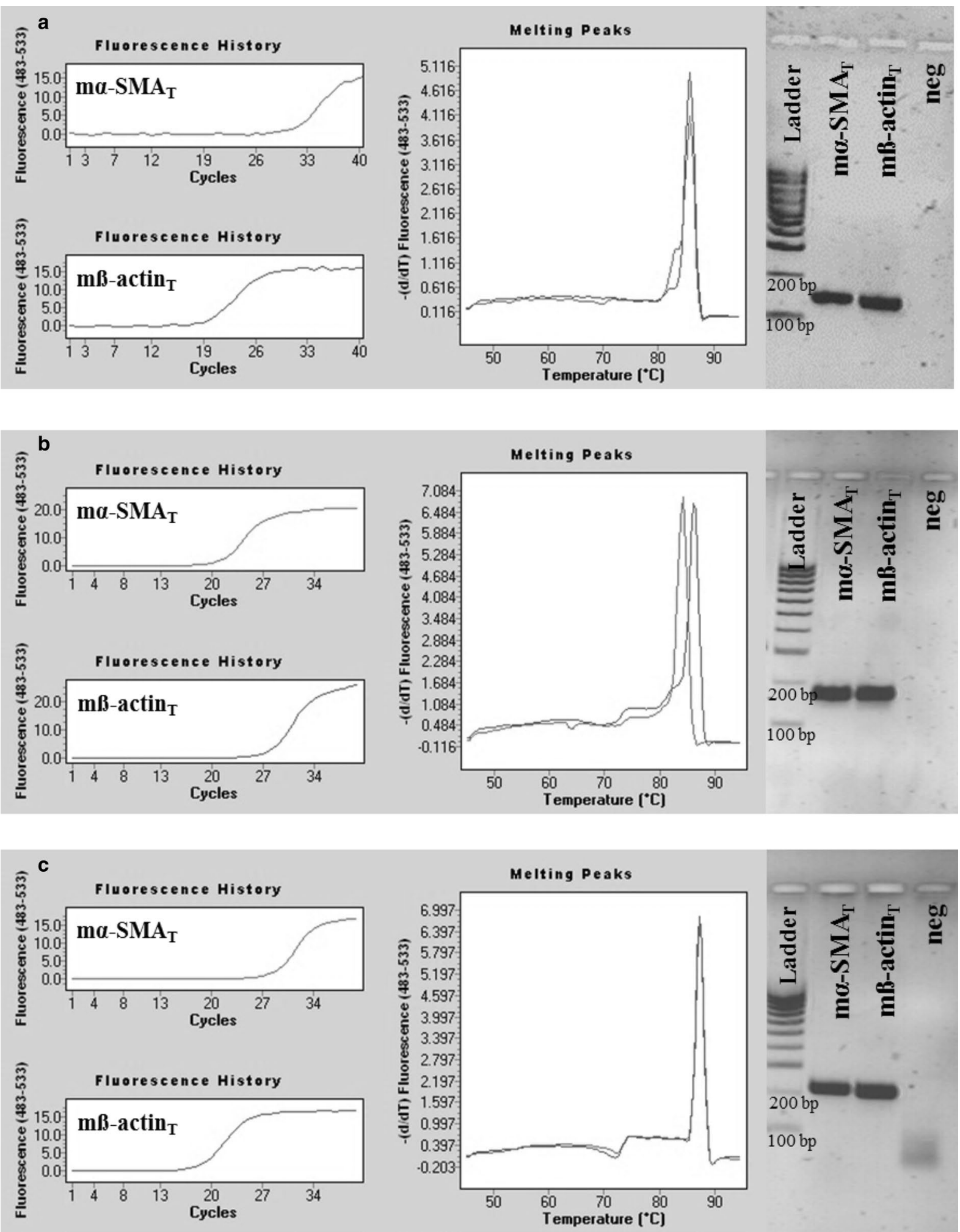

Fig. 8 Representative plots of real-time PCRs using literary primer pairs specific for mouse $\beta$-actin. Real-time $P C R s$ using $m ß$-actin $n_{L 1}, m \beta$-actin ${ }_{L 2}$ or $\mathrm{m} B$-actin $\mathrm{L}_{3}$ primer pairs and $\mathrm{m} \beta$-actin $\mathrm{T}$ DNA templates resulted in products $\left(\mathrm{Ct}_{\mathrm{L} 1}=19.73, \mathrm{Ct}_{\mathrm{L2}}=27.72, \mathrm{Ct}_{\mathrm{L} 3}=18.65\right)$ with single melting peaks at $85.6,86.3$, or $87.4^{\circ} \mathrm{C}$ and in discrete bands in the agarose gel at 60,101 or 154 bp, respectively (a-c). Real-time PCRs using $m ß$-actin ${ }_{L 1}, m_{3}$-actin ${ }_{L 2}$ or $\mathrm{mB}$-actin $\mathrm{L}_{\mathrm{L}}$ literary primer pairs amplified the non-specific ma-SMA $\mathrm{DNA}$ templates also $\left(\mathrm{Ct}_{\mathrm{L} 1}=31.29, \mathrm{Ct}_{\mathrm{L} 2}=21.08, \mathrm{Ct}_{\mathrm{L} 3}=28.43\right)$, resulted in melting peaks at $85.6,84.2$ or $87.4^{\circ} \mathrm{C}$ and indiscrete bands at 60,101 or $154 \mathrm{bp}$, respectively (a-c) 


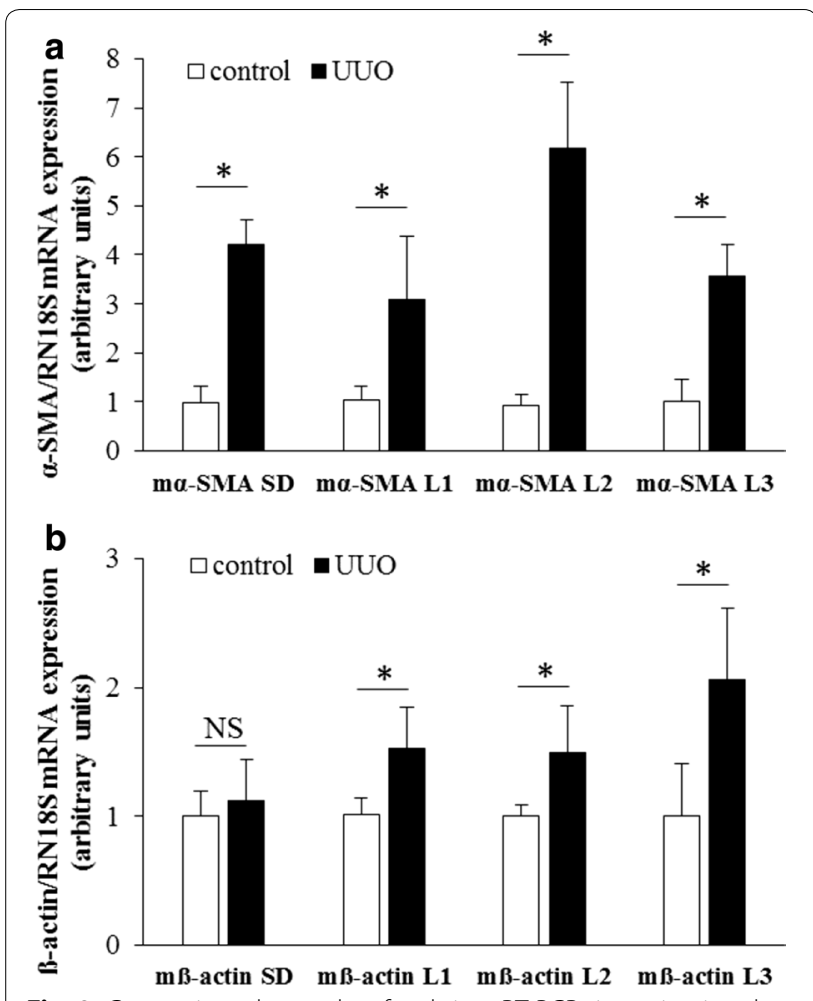

Fig. 9 Comparison the results of real-time RT-PCRs investigating the mRNA expression of a-SMA or ß-actin using our or literary primer pairs. Depending on the applied primer pairs, the increase in mRNA expression of a-SMA varied from 3.1- to 6.2-fold in the kidneys of mice underwent UUO compared to the corresponding controls (a). While using our primer pair there was no difference in the mRNA expression of $ß$-actin, using literary primer pairs increased $B$-actin mRNA expression was detected in the kidney of mice underwent UUO compared to the corresponding controls (b). Results were determined by comparison with RN18S and presented as mean + SD. ${ }^{*} p<0.05$ UUO vs. control

\section{Discussion}

Family of actins comprises six different isoforms, among them $\alpha$-SMA and $\beta$-actin have special importance. Recognizing the medical importance of FDs, the number of studies measuring the expression of $\alpha$-SMA, the biomarker of the MFs, is increasing. Indeed, currently there in no study investigating the pathomechanism of organ fibrosis or aiming the development of new chemical compounds to inhibit fibrosis without measuring the expression of $\alpha$-SMA. The other isoform of major importance is $ß$-actin which is one of the most frequently used housekeeping genes in thousands of studies every year. Although different actin isoforms are encoded by different genes, the homology in their amino acid or nucleotide sequences is over $90 \%$ making it challenging to determine the expression of the given isoform without cross-reactions with the others (Fig. 1) [8].
In the present study, we developed an isoform-specific real-time PCR method to selectively measure the mRNA expression of mouse, human and rat $\alpha$-SMA and $\beta$-actin as well. Moreover, we demonstrated the significance of the inaccuracy caused by the use of non-specific $\alpha$-SMA or $ß$-actin primer pairs in the most frequently used mice model of renal fibrosis.

During PCRs DNA polymerase enzymes start the synthesis of the new DNA strand from the $3^{\prime}$ end of the annealed primers [24]. Mismatches in the $3^{\prime}$ end of the primers significantly determine the proper primerannealing, and as consequence the specificity of the PCRs $[25,26]$. Therefore, we located our different actin primers to nucleotide sequences with the greatest possible difference from other actin isoforms, paying special attention to the $3^{\prime}$ end of our primers to maximize the chance of specific priming (Fig. 1).

In the first set of experiments, target specificity of our mouse $\alpha$-SMA and $\beta$-actin specific primer pairs were tested $\left(\mathrm{m} \alpha-\mathrm{SMA}_{\mathrm{SD}}\right.$ and $\beta$-actin ${ }_{\mathrm{SD}}$, respectively) using chemically synthetized mouse $\alpha$-SMA, $\beta-, \gamma$-cyto- and $\gamma$-smooth-actin gene fragments as templates. Real-time PCRs using specific template of a certain primer pair resulted in products with one separate melting curve maximum, and likewise, in one discrete band with the expected product length during separation by gel electrophoresis. Applying our mouse $\alpha$-SMA specific primer pairs in real-time PCRs containing the non-specific $B$-, $\gamma$-cyto- or $\gamma$-smooth-actin DNA templates (Fig. 2), or our mouse $B$-actin specific primer pair in real-time PCRs containing $\alpha$-SMA, or $\gamma$-smooth actin specific DNA templates, PCR products were not observed (Fig. 3). However, due to the remarkable (nearly 90\%) sequence homology between mouse $\beta$ - and $\gamma$-cyto-actin, we could not eliminate the cross-reaction between our mouse ß-actin primer pair and artificial DNA template corresponding to $\gamma$-cyto-actin. Fortunately, the biological significance of this cross-reaction is small, since both $ß$ - and $\gamma$-cyto-actin are housekeeping genes, and the measurement of these as internal controls can be easily replaced by measuring another one [1]. Taken together, these observations demonstrate that our actin isoform specific primer pairs are suitable for the measurement of the mRNA expression of mouse $\alpha$-SMA and $\beta$-actin, respectively.

In the next step of PCR-validation process, we determined amplification efficiency of our real-time PCRs, using $\mathrm{m} \alpha-\mathrm{SMA}_{\mathrm{SD}}$ or $\mathrm{m} ß$-actin $\mathrm{SD}_{\mathrm{SD}}$ primer pairs. We found that amplification factors derived from the slopes of calibration curves were in the acceptable range from 1.8 to 2.2 (Fig. 5) [27, 28].

In the second set of experiments, the specificity of our mouse $\alpha$-SMA and $\beta$-actin primer pairs were tested on 

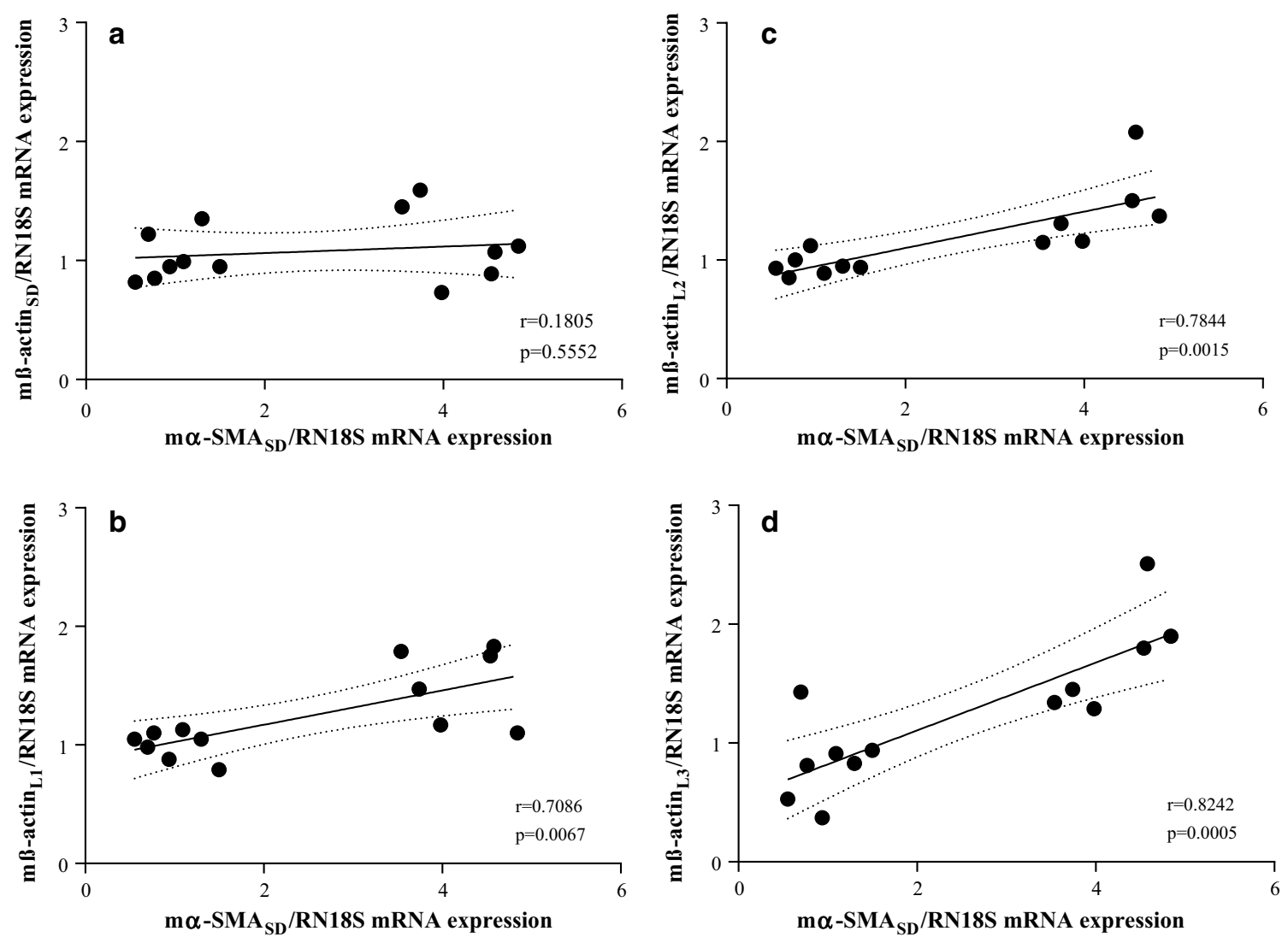

Fig. 10 Correlation between relative a-SMA and B-actin mRNA expression in mice kidneys. The relative $B$-actin mRNA expressions measured by $m ß-\operatorname{actin}_{S D}(\mathbf{a}), m ß-\operatorname{actin}_{L 1}(\mathbf{b}), m ß-\operatorname{actin}_{L 2}(\mathbf{c})$ or $\mathrm{m} ß-\operatorname{actin}_{\mathrm{L} 3}(\mathbf{d})$ primer pairs were correlated with the relative $\mathrm{a}-\mathrm{SMA}$ expressions measured by ma-SMA $A_{S D}$ for each samples

kidney samples of mice underwent UUO, which is a wellcharacterized experimental model of renal fibrosis. It is already well known that after the onset of UUO the number of $\alpha$-SMA expressing MFs is increasing in the kidney in parallel with the development of fibrosis. The simultaneous strong expression of $\alpha$-SMA and $\beta$-actin makes the fibrotic kidney an excellent biological sample to test the possible cross-reaction of our primers and the different actin isoforms. The products of the mouse $\alpha$-SMA and $B$-actin specific real-time RT-PCR were sequenced, and the resulting nucleotide sequences were compared to the CDS of the corresponding actin isoforms (Fig. 4).
The nucleotide sequences of these PCR products were identical to the reference CDS of the amplified genes, and did not show any overlap with the other actin isoform confirming the specificity of our primer pairs. Taken together, all these data suggest that our mouse $\alpha$-SMA and $B$-actin primers are clearly applicable to specifically measure the mRNA expression of mouse $\alpha$-SMA and ß-actin.

In the third set of experiments, investigating the biological relevance of the non-specific primer binding, the template specificity of three mouse $\alpha$-SMA and three $\beta$-actin literary primer pairs were tested. As it was

(See figure on next page.)

Fig. 11 Representative plots of human and rat a-SMA and B-actin specific real-time PCRs. PCRs using ha-SMA $A_{S D}$ or ra-SMA $A_{S D}$ Specific primer pairs amplified the ha-SMA $(C t=32)$ or ra-SMA $(C t=28.21)$ DNA template $\left(\mathbf{a}\right.$, b respectively), but did not amplify the $h \beta$-actin or $_{T} \beta$-actin template $_{T}$ (a, b respectively). Our human or rat a-SMA specific PCRs resulted in products with melting peaks at 81.7 or $82.8^{\circ} \mathrm{C}$, and in discrete bands in

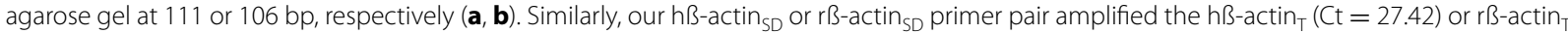
$(C t=25.58)$ DNA template (c, d respectively), but did not amplify the ha-SMA $A_{T}$ or ra-SMA $A_{T}$ template (c, $\mathbf{d}$ respectively). Our human or rat $B$-actin specific PCRs resulted in products with melting peaks at 86 or $83.4^{\circ} \mathrm{C}$, and in discrete bands in agarose gel at 114 or 107 bp, respectively (c, d) 

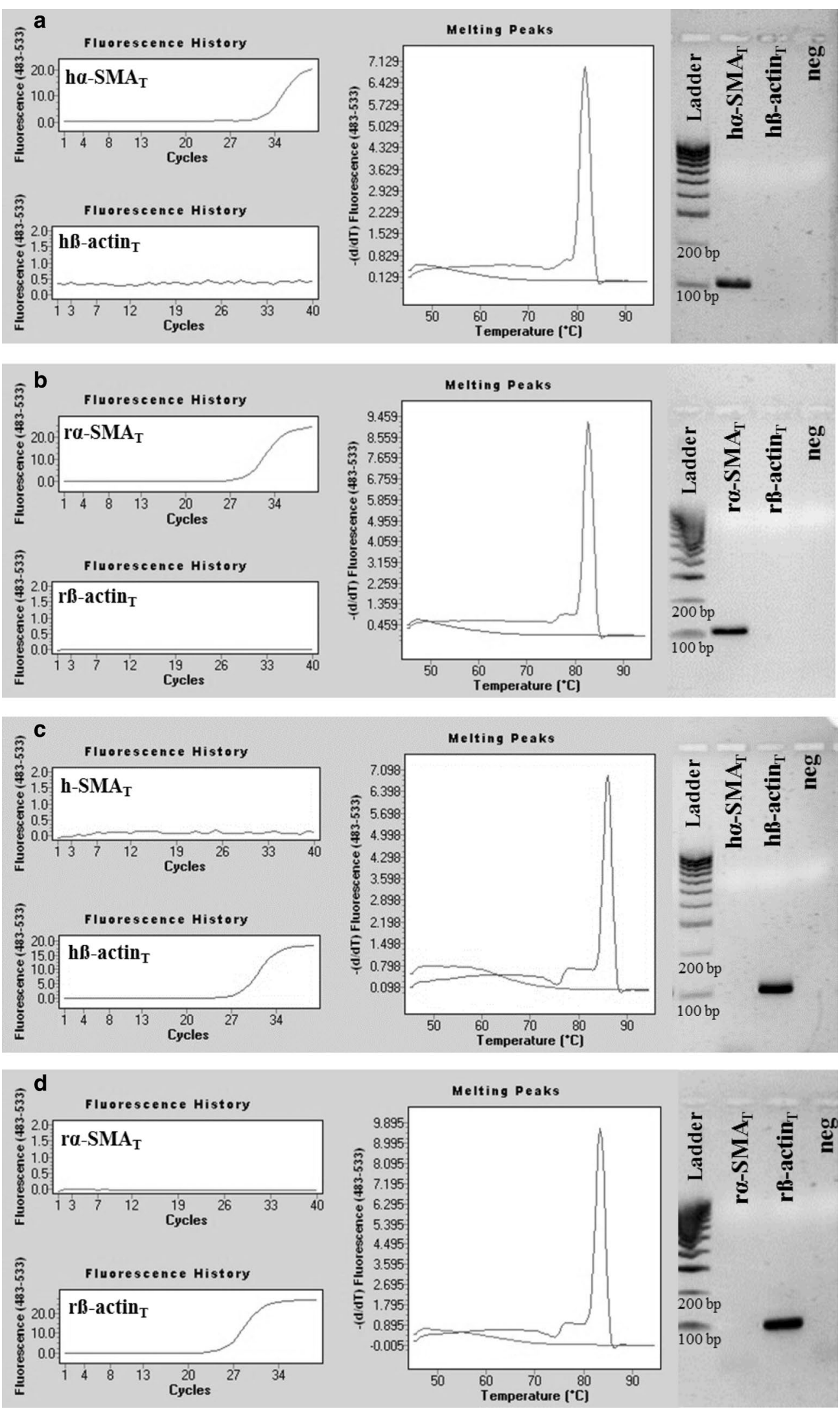
expected, based on the high degree of homology of these primers and the corresponding CDSs (Fig. 6), we found that all primer pairs amplified both mouse $\alpha$-SMA and $ß$-actin specific artificial DNA templates as well (Figs. 7, 8). To investigate the relevance of non-specific primer binding on the experimental results, real-time RT-PCRs were performed on kidney samples of mice underwent UUO and sham-operated controls using the different set of primer pairs. Carried out the measurement with our primer pair, 4.2 fold relative increase was observed in the mRNA expression of $\alpha$-SMA in the kidney of mice underwent UUO compared to the controls. In the cases of literary primer pairs, the fold change values of $\alpha$-SMA mRNA expression varied from 3.0 to 6.2 in the same kidney samples (Fig. 9a), suggesting that the crossreactions of these primers with the different actin isoforms may substantially alter the experimental results. Similarly, while using our carefully designed primer pair, the mRNA expression of $B$-actin was equal in the two groups, applying the literary primer pairs it showed significant increase in the kidney of mice underwent UUO compared to controls (Fig. 9b). These results suggest that cross-reaction between $ß$-actin primer pairs and different actin isoforms, such as $\alpha$-SMA in the fibrotic kidney, may lead to the virtually increased expression of $\beta$-actin, the frequently measured housekeeping gene, in certain experimental conditions [29]. Our observation was confirmed by the high positive, significant correlation between the $\alpha$-SMA expression measured by our primer pair $\left(m-\alpha S M A_{\mathrm{SD}}\right)$ and $\beta$-actin expression measured by not properly designed literary primer pairs (Fig. 10). As a consequence of the inaccurate determination of the housekeeping gene expression it may result in false experimental outcomes and conclusions.

Given the importance of the issue, we also developed human and rat $\alpha$-SMA and $\beta$-actin specific primer pairs. The specificity of these primer pairs were tested in realtime PCRs using artificial DNA templates corresponding to human or rat $\alpha$-SMA and $\beta$-actin similarly to that described above. Results of these experiments suggest that our primer pairs can specifically bind to their target DNA allowing the specific measurement of the mRNA expression of human and rat $\alpha$-SMA and $\beta$-actin as well (Fig. 11).

\section{Conclusions}

In summary, as the number of studies investigating the behavior of the MFs-the main effector cells of fibrosisis increasing, so get more important the precise determination of $\alpha$-SMA expression. In the present study we developed a set of carefully designed mouse, human and rat $\alpha$-SMA specific primer pairs to determine the expression of $\alpha$-SMA without cross reactions with other highly homologue actin isoforms. Our study also give an experimental explanation, how the cross reaction between different actin isoforms can influence the measurements concerning the expression of housekeeping gene $B$-actin, underlining the importance of proper primer design.

\begin{abstract}
Abbreviations
a-SMA: a smooth muscle actin; bp: base pair; CDS: coding sequence; Ct: threshold cycle; FD: fibroproliferative disease; h: human; L: literary; m: mouse; MF: myofibroblast; r: rat; RN18S: 18s ribosomal RNA; SD: self-designed; T: artificial DNA template; UUO: unilateral ureteral obstruction.
\end{abstract}

\section{Authors' contributions}

AV conceived and designed the experiments. AVS designed the primers and analyzed the data. DP performed the animal model. RR, RL performed the PCRs. KT and EJ performed the sequencing. AJS, TT and AV coordinated the research. AVS, DP, ES, AF and AV drafted and edited the manuscript. All authors read and approved the final manuscript.

\section{Author details}

${ }^{1}$ MTA-SE Pediatrics and Nephrology Research Group, Budapest, Hungary. ${ }^{2}$ 1st Department of Pediatrics, Semmelweis University, Budapest, Hungary. ${ }^{3}$ MTASE "Lendulet" Nephrogenetic Research Group, Budapest, Hungary. ${ }^{4}$ MTA-SE "Lendulet" Diabetes Research Group, Budapest, Hungary.

\section{Acknowledgements}

We are grateful to Mária Bernáth for her excellent technical assistance.

\section{Competing interests}

The authors declare that they have no competing interests.

Availability of data and materials

The datasets during the current study available from the corresponding author on reasonable request.

\section{Ethics approval and consent to participate}

The institutional committee on animal welfare approved all experiments (PEI/ 001/83-4/2013).

\section{Funding}

This work was supported by Hungarian National Scientific Research Foundation Grants-OTKA K1 16928, NN114607, PD105361; LP2015-11/2015 and LP2011-008/2016.

\section{Publisher's Note}

Springer Nature remains neutral with regard to jurisdictional claims in published maps and institutional affiliations.

Received: 12 August 2016 Accepted: 20 April 2017

Published online: 27 April 2017

\section{References}

1. Axtner J, Sommer S. Validation of internal reference genes for quantitative real-time PCR in a non-model organism, the yellow-necked mouse, Apodemus flavicollis. BMC Res Notes. 2009;2(1):264.

2. Wynn TA. Common and unique mechanisms regulate fibrosis in various fibroproliferative diseases. J Clin Investig. 2007;117(3):524-9.

3. Wynn TA. Cellular and molecular mechanisms of fibrosis. J Pathol. 2008;214(2):199-210.

4. Liu Y. Cellular and molecular mechanisms of renal fibrosis. Nat Rev Nephrol. 2011;7(12):684-96.

5. CoxTR, Erler JT. Remodeling and homeostasis of the extracellular matrix: implications for fibrotic diseases and cancer. Dis Models Mech. 2011;4(2):165-78. 
6. Hinz B. Formation and function of the myofibroblast during tissue repair J Investig Dermatol. 2007;127(3):526-37.

7. Lemoinne S, Cadoret A, El Mourabit H, Thabut D, Housset C. Origins and functions of liver myofibroblasts. Biochimica et Biophysica Acta Mol Basis Dis. 2013;1832(7):948-54.

8. Perrin BJ, Ervasti JM. The actin gene family: function follows isoform. Cytoskeleton. 2010;67(10):630-4

9. Livak KJ, Schmittgen TD. Analysis of relative gene expression data using real-time quantitative PCR and the $2^{-} \triangle \triangle C T$ method. Methods. 2001;25(4):402-8.

10. Pfaffl MW. Quantification strategies in real-time PCR. In: Bustin $S A$, editor AZ of quantitative PCR. La Jolla: International University Line; 2004. p. 87-112.

11. Valasek MA, Repa JJ. The power of real-time PCR. Adv Physiol Educ. 2005;29(3):151-9.

12. Heim M, Meyer UA. Genotyping of poor metabolisers of debrisoquine by allele-specific PCR amplification. Lancet. 1990;336(8714):529-32.

13. NCBI reference sequence database. http://www.ncbi.nlm.nih.gov/refseq/ Accessed 12 Aug 2016.

14. Primer3web software version 4.0.0. http://bioinfo.ut.ee/primer3/. Accessed 12 Aug 2016.

15. Bechtel W, McGoohan S, Zeisberg EM, Müller GA, Kalbacher H, Salant D Müller CA, Kalluri R, Zeisberg M. Methylation determines fibroblast activation and fibrogenesis in the kidney. Nat Med. 2010;16(5):544-50.

16. Zeisberg EM, Tarnavski O, Zeisberg M, Dorfman AL, McMullen JR, Gustafsson E, Chandraker A, Yuan X, Pu WT, Roberts AB, Neilson EG. Endothelialto-mesenchymal transition contributes to cardiac fibrosis. Nat Med. 2007;13(8):952-61.

17. Henderson NC, Arnold TD, Katamura Y, Giacomini MM, Rodriquez JD, McCarty JH, Pellicoro A, Raschperger E, Betsholtz C, Ruminski PG, Griggs DW. Targeting of [alpha] $v$ integrin identifies a core molecular pathway that regulates fibrosis in several organs. Nat Med. 2013;19(12):1617-24.

18. Hecker L, Vittal R, Jones T, Jagirdar R, Luckhardt TR, Horowitz JC, Pennathur S, Martinez FJ, Thannickal VJ. NADPH oxidase-4 mediates myofibroblast activation and fibrogenic responses to lung injury. Nat Med. 2009;15(9):1077-81.
19. Hao S, He W, Li Y, Ding H, Hou Y, Nie J, Hou FF, Kahn M, Liu Y. Targeted inhibition of $\beta$-catenin/CBP signaling ameliorates renal interstitial fibrosis. I Am Soc Nephrol. 2011;22(9):1642-53.

20. LeBleu VS, Taduri G, O'connell J, Teng Y, Cooke VJ, Sugimoto H, Kalluri R. Origin and function of myofibroblasts in kidney fibrosis. Nat Med. 2013;19(8):1047-53.

21. LeBleu VS, Teng Y, O'Connell J, Charytan D, Müller GA, Müller CA, Sugimoto H, Kalluri R. Identification of human epididymis protein-4 as a fibroblast-derived mediator of fibrosis. Nat Med. 2013:19(2):227-31.

22. Zeybel M, Hardy T, Wong YK, Mathers JC, Fox CR, Gackowska A, Oakley F, Burt AD, Wilson CL, Anstee QM, Barter MJ. Multigenerational epigenetic adaptation of the hepatic wound-healing response. Nat Med. 2012;18(9):1369-77.

23. Mukaka MM. A guide to appropriate use of correlation coefficient in medical research. Malawi Med J. 2012;24(3):69-71.

24. Mullis K, Faloona F, Scharf S, Saiki RK, Horn GT, Erlich H. Specific enzymatic amplification of DNA in vitro: the polymerase chain reaction. Cold Spring Harb Symp Quant Biol. 1986;51:263-73.

25. Dieffenbach CW, Lowe TM, Dveksler GS. General concepts for PCR primer design. PCR Methods Appl. 1993;3(3):S30-7.

26. Nolan T, Hands RE, Bustin SA. Quantification of mRNA using real-time RT-PCR. Nat Protoc. 2006:1 (3):1559-82.

27. Zhang Q, et al. Tqper: a touchdown qpcr assay with significantly improved detection sensitivity and amplification efficiency of sybr green qpcr. PLoS ONE. 2015;10(7):e0132666.

28. Bustin SA, et al. The MIQE guidelines: minimum information for publication of quantitative real-time PCR experiments. Clin Chem. 2009;55(4):611-22.

29. Lin J, Redies C. Histological evidence: housekeeping genes beta-actin and GAPDH are of limited value for normalization of gene expression. Dev Genes Evol. 2012;222(6):369-76.

\section{Submit your next manuscript to BioMed Central and we will help you at every step:}

- We accept pre-submission inquiries

- Our selector tool helps you to find the most relevant journal

- We provide round the clock customer support

- Convenient online submission

- Thorough peer review

- Inclusion in PubMed and all major indexing services

- Maximum visibility for your research

Submit your manuscript at www.biomedcentral.com/submit
O) BioMed Central 